\title{
No Hiking Beyond this Point! Hiking Risk Prevention Recommendations in Peer- Reviewed Literature
}

\section{Authors: Katherine V. Kortenkamp, Colleen F. Moore, Daniel P. Sheridan, and Emily S. Ahrens}

NOTICE: this is the author's version of a work that was accepted for publication in Journal of Outdoor Recreation and Tourism. Changes resulting from the publishing process, such as peer review, editing, corrections, structural formatting, and other quality control mechanisms may not be reflected in this document. Changes may have been made to this work since it was submitted for publication. A definitive version was subsequently published in Journal of Outdoor Recreation and Tourism, v. 20, December 2017, DOI\#10.1016/j.jort.2017.10.002.

Kortenkamp, Katherine V. , Colleen F. Moore, Daniel P. Sheridan, and Emily S. Ahrens. "No Hiking Beyond this Point! Hiking Risk Prevention Recommendations in Peer-Reviewed Literature." Journal of Outdoor Recreation and Tourism 20 (December 2017): 67-76. DOI: 10.1016/j.jort.2017.10.002.

Made available through Montana State University's $\underline{\text { ScholarWorks }}$ scholarworks. montana.edu 


\title{
No Hiking Beyond this Point! Hiking Risk Prevention Recommendations in Peer-Reviewed Literature
}

\author{
Katherine V. Kortenkamp ${ }^{\mathrm{a}, *}$, Colleen F. Moore ${ }^{\mathrm{b}, \mathrm{c}}$, Daniel P. Sheridan ${ }^{\mathrm{a}}$, Emily S. Ahrens ${ }^{\mathrm{a}}$ \\ a University of Wisconsin-La Crosse, Psychology Department, 1725 State St, La Crosse, WI 54601, USA \\ ${ }^{\mathrm{b}}$ Montana State University-Bozeman, Psychology Department, USA \\ ${ }^{c}$ University of Wisconsin-Madison, Psychology Department, USA
}

\begin{abstract}
A B S T R A C T
Outdoor recreation in wild areas has many benefits, but also poses risks. We conducted a systematic review of the prevention recommendations in peer-reviewed articles about hiking incidents (injury, illness, or need for rescue) published between 1970 and 2015. Searches in PubMed, Web of Science, and Engineering Village yielded 91 articles after screening for relevance. A total of 559 prevention recommendations were extracted from articles. The foci of the recommendations were categorized using a systems-oriented approach to accident prevention, an adapted Haddon matrix. Five non-mutually exclusive categories were used: hiker, groups and relationships, agent inducing the incident, institutions and sociocultural practices, and equipment. We also coded prevention recommendations that pertained to education within each of the five categories. Sixty percent of the prevention recommendations focused on changing the hiker's decisions and behaviors, and $39 \%$ referred to institutions and sociocultural practices. Few addressed the social influences of groups and relationships (8\%), equipment $(16 \%)$, or the agent of harm $(16 \%)$. Education was the focus of $27 \%$ of the recommendations. We conclude that effective prevention needs to include multiple aspects of outdoor recreation systems and their interactions with the hiker's behavior and characteristics.

Management implications: This systematic review introduces outdoor recreation managers to the systems-oriented Haddon matrix framework for accident prevention in outdoor recreation. By using this framework, this paper:
\end{abstract}

1. Views accidents as resulting from interactions of individuals with both social and physical environments.

2. Highlights areas for prevention that tend to be missing from published safety recommendations (groups, agent of harm, and equipment).

3. Gives examples of how managers can look at outdoor risk prevention from a broader perspective in order to find innovative solutions to common accidents and rule violations.

Outdoor recreation in natural areas has psychological and physical health benefits (e.g., Kaplan \& Berman, 2011; Thompson \& Aspinall, 2011). Recreation in natural settings also poses risks of injury and illness that can lead to considerable costs. For example, between 1992 and 2007, there was an average of 11.2 search and rescue operations each day in U.S. National Parks for a total cost of over \$58.5 million (Heggie \& Amundson, 2009). Like other research on public health issues, research on accidents and illnesses in outdoor recreation such as day hiking and backpacking is conducted with the ultimate goal of reducing the incidence of such events by advancing scientific understanding. The objectives of this systematic review were to extract and categorize prevention recommendations from peer-reviewed publications on outdoor recreational accidents with an emphasis on hiking in the United States. Prevention recommendations found in peer-reviewed publications are important because they indicate the status of current thinking of scholars about prevention, and it is scholars involved in empirical research who are likely to be responsible for developing and testing evidence-based prevention strategies. By highlighting the 
prevention recommendations in peer-reviewed literature, we hope the results of this study can inform and inspire future research developing an evidence basis for recommendations that could reduce search-andrescue and other hiking incidents in the U.S.

This article focuses primarily on hiking as an outdoor recreation. Hiking has become increasingly popular over the last several decades. According to the National Survey of Recreation and the Environment conducted by the U.S. Forest Service, approximately $12 \%$ of Americans participate in hiking (Cordell, 2012). Most studies find that hiking incidents represent a large percentage of search and rescue (SAR) and other incidents requiring interventions, although percentages can vary widely depending on locale. For example, Heggie and Amundson (2009) found that $48 \%$ of SAR incidents in U.S. National Parks between 1992 and 2007 were hiking related. Another study found that almost $60 \%$ of recent incidents in Yosemite National Park SAR involved hiking, and $46 \%$ of all incidents involved hiking on trail (Boore \& Bock, 2013). An earlier review of incidents in eight California National Parks found that 31\% involved hiking (Montalvo, Wingard, Bracker, \& Davidson, 1998). In addition, 90\% of heat-related illness incidents in Grand Canyon involved hikers (Noe, Choudhary, Cheng-Dobson, Wolkin, \& Newman, 2013), and $45 \%$ of incidents in Shenandoah National Park involved hiking (Forrester \& Holstege, 2009).

Statistics establishing the risk of hiking versus other outdoor activities are difficult to establish because it is not feasible for institutions managing the many outdoor areas to collect data on the percentage of total users involved in hiking versus other activities. For example, in a review of SAR incidents in U.S. National Parks, Heggie and Heggie (2009) state that their "study was limited by a lack of accurate visitation data and specific participation rates to use as denominators in determining the proportion of participation in recreational activities" (p. 26). Even for the Appalachian trail, estimating the number of hikers is complex (Zarnoch, Bowker, \& Cordell, 2011). Nevertheless, the percentages cited above show that injuries and illnesses while hiking are a significant public health concern.

From the peer-reviewed literature focusing on hiking incidents, we extracted hiking injury and illness prevention recommendations and classified them using a Haddon matrix (Haddon, 1980, 1995). The Haddon matrix is regarded as having brought epidemiological concepts fully into the injury control literature and has been widely applied in prevention research, covering topics such as motor vehicle accidents, falls, and injuries during ambulance transport (Brice et al., 2012; Runyan \& Baker, 2009). The Haddon matrix organizes factors contributing to an injury or illness event into categories: host/human, agent/vector, and the physical and social environments (Haddon, 1980; Runyan \& Yonas, 2008). The host/human is the person experiencing the illness or injury. The agent/vector, in the case of illnesses, is the infective substance such as a bacterium or virus. In the case of injury, the agent is the means of energy transfer to the host that induces the injury, such as the repeated impact of the foot on rocks or the impact of the human body with parts of a vehicle in an automobile crash. The physical and social environments are the contexts in which the event occurs. Runyan and Yonas (2008) expanded the framework to include relationships and enhanced the sociocultural context.

Importantly, the Haddon matrix promotes conceptualizing injury and illness events as resulting from "interactions among the host, agent, and environment" (Runyan, 2003, p. 60); therefore, bringing the Haddon matrix into the literature on outdoor recreation accidents and illnesses has potential to broaden the current thinking about prevention. To our knowledge the Haddon matrix has only rarely been used for outdoor accidents (see Gruen, 2009, for conceptual application of a Haddon matrix to reducing crocodile attacks in Australia). Using a Haddon matrix in the present context provides a comprehensive way of thinking about the possible countermeasures to reduce both the frequency and severity of outdoor injuries and illnesses

The Haddon matrix differs from methods of 'accident analysis" such as the "Accimap" (Rasmussen, 1997) or "STAMP" (Leveson, 2004), although both involve thinking about the entire context in which an incident is situated. Accident analysis methods focus on identifying the causes of accidents and injuries and can inform the development of needed system changes and accident prevention measures (Salmon, Cornelissen, \& Trotter, 2012), whereas the main goal of the Haddon matrix is to identify prevention strategies (primary, secondary and tertiary) in a situation with a risk of injury or illness (Haddon, 1980). Since this study was focusing on prevention strategies, the Haddon matrix was used rather than accident analysis. In addition, we did not use accident analysis because those methods require a level of detail that is usually not available in outdoor recreation accident reports (Goode, Salmon, Lenné, \& Finch, 2015).

Recent research on accident and prevention analysis in other areas has noted the prevalence of prevention recommendations focused on changing the victim's behavior, while at the same time highlighting the importance of taking a broader systems approach to prevention and making recommendations for changes at all levels (e.g., physical, social, institutional; see Goode et al., 2015, for an example). Following this trend, we expected that the outdoor risk prevention strategies found in peer-reviewed articles would primarily be targeted at changing the behavior of the participant in the outdoor activity, the hiker.

\section{Method}

\subsection{Search strategy}

Peer-reviewed articles (including published conference papers) were located in PubMed, Web of Science, and Engineering Village using the time frame $1 / 1 / 1970$ to $12 / 31 / 2015$. The search terms used were a combination of (hike* or hiking* or wilderness ${ }^{\star}$ ) and (injur ${ }^{*}$ or illness* or accident*). Fig. 1 gives the resulting numbers of articles found in each database. Titles and abstracts were initially screened for inclusion by the first author. We excluded any articles as well as any prevention recommendations focused only on motorized outdoor recreation, watercraft, swimming, bicycles, snow recreation, technical climbing, hunting, or fishing unless these articles also included hiking. We excluded purely technical climbing, but not articles that covered approach hiking. As mentioned previously, we focused on hiking because it is typically found to be the most common activity associated with outdoor

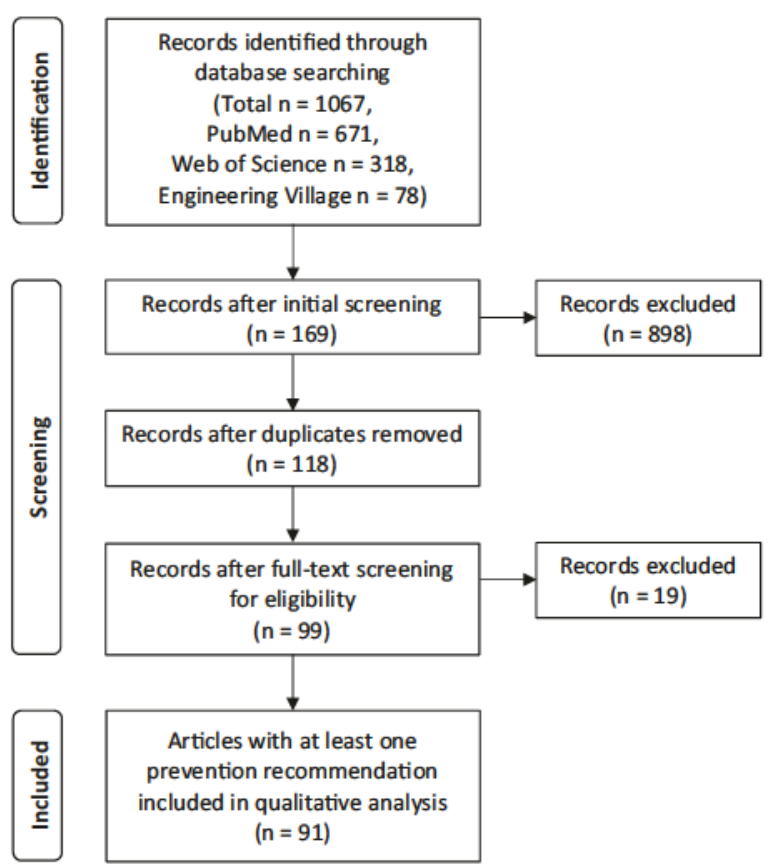

Fig. 1. Flow diagram illustrating the number of journal articles found in the databases searched, screened for eligibility, and included in the analysis. 
recreation injuries and illnesses. The other activities listed above were excluded because they would likely have very specific and often technical recommendations that only applied to that specific activity category. In addition, we excluded the following: papers discussing only non-U.S. based results; non-peer reviewed literature; case reports; society guidelines for medical practices; pre-participation screening guidelines for doctors; teaching wilderness medicine to medical students; methods of differential diagnosis and medical treatments of injuries and illnesses; long term aftereffects of injuries and illnesses; and firefighting, military, or other vocational incidents. After the initial screening of titles and abstracts, each article was read by at least one of the authors, and further screening brought the pool of articles down to 91 articles that met inclusion criteria and contained at least one prevention recommendation. Eight additional articles met the criteria for inclusion but contained no prevention recommendations.

\subsection{Extracting and categorizing prevention recommendations}

Since the Haddon matrix has rarely been applied to outdoor risks, the first step in this analysis was to extract an initial random sample of prevention recommendations to be used to define and refine the coding categories in the matrix so they would be most applicable. The next steps were to establish inter-rater reliability and code all remaining articles. This type of procedure is commonly used in quantitative content analysis (Krippendorff, 2004). These steps are described in detail below.

From the pool of relevant articles, five articles were randomly selected, and each of the four authors extracted prevention recommendations from the abstract, results, and discussion sections of those articles. Prevention statements included recommendations of practices that the article authors suggested would be beneficial for reducing accidents, injuries, or illnesses. Most of these statements were recommendations for the future, but some were practices already in place that the authors suggested were effective. The prevention statements were copied verbatim from the articles with page numbers. Any duplicate statements were copied but not further coded. All authors discussed and finalized the list of prevention statements $(n=39)$ from these five articles.

Then the authors each separately categorized the 39 prevention statements according to the Haddon matrix adapted from Runyan and Yonas (2008). The Haddon matrix is a framework for organizing injury prevention ideas according to whether the idea is designed to change a specific factor (the host, agent, or physical or social environment) during a specific time period (pre-event, during the event, or postevent) (Runyan \& Yonas, 2008). Runyan and Yonas (2008) adapted the matrix to align more with a sociocultural model and thus included an additional "relationships" factor as well as explicitly including separate categories for "institutions" and "sociocultural practices" under the social and physical environment. We added a separate "equipment" factor, as it was highly relevant for this particular topic.

After the initial categorizations using this matrix, the four co-authors discussed agreements and disagreements as well as the usefulness of the matrix categories. After discussion, the Haddon matrix was simplified by removing the time period dimensions. The authors found it difficult to disentangle when many of the prevention recommendations were targeted to have their desired effect. For example, recommendations involving hikers being better prepared or requiring safety training could ostensibly have a beneficial impact pre-, during, and post-event. It was also difficult to decide where to place the cutoffs for pre-, during, and post-event because the events vary a great deal in the literature (e.g., ankle sprains, diarrhea, altitude sickness, fatalities). We also recombined "institutions" and "sociocultural practices" into one category (Runyan \& Yonas, 2008, separated them, but Haddon, 1980 , originally did not) due to overlap between them (e.g., changes to government policies would be a sociocultural practice change but also require an institutional change in the enforcement of those policies).
Table 1

Frequency and percent of prevention recommendations in each Haddon matrix category and inter-rater reliability coefficients.

\begin{tabular}{llllll}
\hline & \multicolumn{5}{c}{ Coding categories } \\
\cline { 2 - 6 } Recommendations & Hiker & $\begin{array}{c}\text { Groups \& } \\
\text { relationships }\end{array}$ & $\begin{array}{c}\text { Agent } \\
\text { of } \\
\text { harm }\end{array}$ & $\begin{array}{c}\text { Institutions \& } \\
\text { sociocultural } \\
\text { practices }\end{array}$ & Equipment \\
\hline All $(N=559)$ & 336 & 47 & 88 & 216 & 87 \\
Educational only & $76 \%$ & $8 \%$ & $16 \%$ & $39 \%$ & $16 \%$ \\
$(n=152)$ & $50 \%$ & $5 \%$ & 5 & 85 & 12 \\
& .90 & .94 & $3 \%$ & $56 \%$ & $8 \%$ \\
$\begin{array}{c}\text { Proportion of } \\
\text { agreement }\end{array}$ & .80 & .54 & .90 & .88 & .90 \\
Cohen's kappa & .80 Reliability coefficients & .65 \\
\hline
\end{tabular}

Note. Categories are not mutually exclusive.

Finally, we added a dimension of "education recommendations" to identify the recommendations in each category that were specifically about education since this seemed to be a prevalent prevention strategy. These recommendations might pertain to the need for educating the hiker, park staff, or medical professionals or how best to carry out education efforts.

Table 1 presents the final adapted Haddon matrix used for coding, and each category is briefly described below. In order to decide if a prevention recommendation fit into a particular category the following sentence-completion exercise adapted from Runyan and Yonas (2008) was used: "__ [the listed recommendation] is an intervention designed to change __ [the category]." A single recommendation often fit into multiple categories, thus categories are not mutually exclusive.

\subsubsection{Hiker}

This was the category originally labeled "host/human" in Haddon's matrix and is the person experiencing the injury or illness. Recommendations suggesting the hiker obey signs, better prepare for a trip, or bring proper equipment would be examples fitting into this category.

\subsubsection{Groups and relationships}

This category includes others involved with the hiker such as hiking companions, other park visitors, family members, or personal doctors. Example recommendations that would fall into this category would include suggestions for how to set up group campsites to decrease spread of illnesses, advice for primary care doctors to be better informed about their patients' outdoor risks, or tips about how to keep children safe in family groups.

\subsubsection{Agent of harm}

The agent is the direct cause of the injury (e.g., impact with rugged terrain, carrying heavy backpacks) or illness (e.g., virus, bacteria, heat, altitude). Recommendations that would be designed to change the agent of harm would include things like applying sunscreen, washing hands, wearing lighter backpacks, and filtering water.

\subsubsection{Institutions and sociocultural practices}

This category includes the park staff, management practices, hospitals, general doctors, rules and regulations, governmental or regulating agencies, etc. This category would include recommendations pertaining to increasing park rangers, educating EMTs, or enforcing park policies.

\subsubsection{Equipment}

This could be personal (e.g., footwear, water disinfection devices) or professional (e.g., medical equipment, accident databases). Prevention suggestions might be to carry certain equipment, modify the equipment 
Table 2

Articles that met all screening criteria and contained at least one prevention recommendation.

\begin{tabular}{|c|c|}
\hline Author(s) (year) & $\begin{array}{l}\text { Number of prevention } \\
\text { recommendations }\end{array}$ \\
\hline Anderson et al. (2009) & 1 \\
\hline Attarian (2010) & 7 \\
\hline Attarian (2015) & 11 \\
\hline Backer (2002) & 12 \\
\hline Backer, Shopes, and Collins (1993) & 9 \\
\hline Backer, Shopes, Collins, and Barkan (1999) & 3 \\
\hline Baker and McKay (2010) & 11 \\
\hline Boore \& Bock (2013) & 11 \\
\hline Boulware (2003) & 2 \\
\hline Boulware (2004b) & 3 \\
\hline Boulware (2004a) & 4 \\
\hline Boulware and Beisang (2005) & 2 \\
\hline Boulware, Forgey, and Martin (2003) & 7 \\
\hline Burdick and Brozen (2003) & 1 \\
\hline Burtscher, Pachinger, Schocke, and Ulmer (2007) & 3 \\
\hline Chang, Koval, Freer, and Kraus (2000) & 3 \\
\hline Cherington (2001) & 11 \\
\hline Cowdin (1986) & 5 \\
\hline Crouse and Josephs (1993) & 15 \\
\hline DeClerck, Atterton, Seibert, and Cushing (2013) & 5 \\
\hline Ela (2004) & 8 \\
\hline Elliott, Elliott, and Bixby (2003) & 1 \\
\hline Flores, Haileyesus, and Greenspan (2008) & 12 \\
\hline Floyd (1999) & 44 \\
\hline Forrester and Holstege (2009) & 4 \\
\hline Freer (1999) & 4 \\
\hline Freer (2004) & 12 \\
\hline Gardner and Hill (2002) & 4 \\
\hline Gaudio, Greenwald, and Holton (2011) & 10 \\
\hline Gentile, Morris, Schimelpfenig, Bass, and Auerbach (1992) & 6 \\
\hline Girasek, Marschall, and Pope (2016) & 4 \\
\hline Goodman, Iserson, and Strich (2001) & 6 \\
\hline Grissom, Thomas, and James (2006) & 29 \\
\hline Hamonko, McIntosh, Schimelpfenig, and Leemon (2011) & 6 \\
\hline Heggie (2005) & 8 \\
\hline Heggie (2008) & 1 \\
\hline Heggie (2010) & 13 \\
\hline Heggie, Amundson et al. (2009) & 1 \\
\hline Heggie and Heggie (2004) & 9 \\
\hline Heggie and Heggie (2008) & 1 \\
\hline Heggie and Heggie (2009) & 5 \\
\hline Heggie, Heggie and Heggie (2009) & 1 \\
\hline Heggie, Heggie, and Kliewer (2008) & 2 \\
\hline Ho, Speck, and Kumasaki (2009) & 1 \\
\hline Hung and Townes (2007) & 10 \\
\hline Hurtado (2010) & 8 \\
\hline Johnson, Huettl, Kocsis, Chan, and Kordick (2007) & 2 \\
\hline Johnson et al. (1991) & 9 \\
\hline Kadesky et al. (1998) & 9 \\
\hline Knott (2011) & 9 \\
\hline Kogut and Rodewald (1994) & 4 \\
\hline Langley (2005) & 6 \\
\hline Langley (2010) & 8 \\
\hline Langley and Morrow (1997) & 8 \\
\hline Lathrop (2007) & 3 \\
\hline Leemon and Schimelpfenig (2003) & 2 \\
\hline Mason, Suner, and Williams (2013) & 4 \\
\hline McIntosh, Brillhart, Dow, \& Grissom (2010) & 8 \\
\hline McIntosh, Leemon, Visitacion, Schimelpfenig, and Fosnocht (2007) & 10 \\
\hline McLaughlin, Gessner, and Bailey (2005) & 5 \\
\hline Montalvo et al. (1998) & 1 \\
\hline Morandi and Williams (1997) & 3 \\
\hline Mort and Godden (2011) & 4 \\
\hline Newman, Diekema, Shubkin, Klein, and Quan (1998) & 5 \\
\hline Noe et al. (2013) & 4 \\
\hline O'Neil, Mack, Gilchrist, and Wozniak (2007) & 1 \\
\hline Paton (1992) & 2 \\
\hline Platts-Mills and Hunold (2013) & 1 \\
\hline Pope and Martin (2011) & 2 \\
\hline Powell (2007) & 10 \\
\hline Rotz et al. (1998) & 14 \\
\hline Russell et al. (2013) & 4 \\
\hline Sadeghi, Konwinski, and Cydulka (2015) & 4 \\
\hline Schmidt et al. (1996) & 1 \\
\hline Schussman, Lutz, Shaw, and Bohn (1990) & 9 \\
\hline Shepherd, Mills, and Shoff (2014) & 6 \\
\hline
\end{tabular}

Table 2 (continued)

\begin{tabular}{ll}
\hline Author(s) (year) & $\begin{array}{l}\text { Number of prevention } \\
\text { recommendations }\end{array}$ \\
\hline Stephanides and Vohra (2007) & 4 \\
Stephens, Diekema, \& Klein (2005) & 4 \\
Stewart et al. (2000) & 6 \\
Townes, Laughlin, and Rubio-Derhammer (2000) & $\mathbf{8}$ \\
Trayers (2004) & 7 \\
Twombly and Schussman (1995) & 6 \\
Vann et al. (2005) & 2 \\
Wagner, Fargo, Parker, Tatsugawa, and Young (2006) & 2 \\
Weichenthal et al. (2011) & 6 \\
Weichenthal and Hendey (1998) & 3 \\
Welch (1997) & 3 \\
Welter, Sholl, Strout, and Woodard (2015) & 4 \\
Windsor, Firth, Grocott, Rodway, and Montgomery (2009) & 1 \\
Zell (1992) & 6 \\
Zell and Sorenson (1993) & 3 \\
& Total = 559 \\
\hline
\end{tabular}

that is available, or use equipment in a specific way.

Following these preliminary steps to establish the coding matrix, in order to test inter-rater reliability, pairs of coders independently extracted 52 prevention recommendations $(9.3 \%$ of total recommendations) from another eleven articles ( $12 \%$ of articles) and then categorized these recommendations. Reliability was calculated as both proportion of agreement and Cohen's kappa for each category in the matrix separately because the categories are not mutually exclusive (see Table 1). Reliability was acceptable; kappa was only low in the "groups" category because so few recommendations fit in that category (4/52). After calculating reliability, disagreements were resolved by discussion. Following the establishment of inter-rater reliability, the four authors divided the remaining articles and extracted and categorized the prevention recommendations. Any questions that arose were resolved through discussion.

\section{Results}

Table 2 presents a list of the 91 studies that we analyzed, along with the number of prevention recommendations found in each study. Table 1 displays the frequency of prevention recommendations found in each category of the Haddon matrix. Only $1.3 \%$ of the recommendations $(n=7)$ did not fit into any of the categories. Fig. 2 presents the proportion of educational and non-educational recommendations in each category. Within each category we looked for general themes in the content of the prevention strategies, and below we report on those general themes and provide examples from the papers.

\subsection{Hiker}

As expected, prevention recommendations most commonly targeted changing the behavior of the hiker or outdoor recreation participant. The content of these recommendations focused on increasing awareness ("... waterfall visitors can mitigate the possibility of slipping by being more aware of slippery surfaces," Attarian, 2015, p. 106), being prepared ("... backpackers should expect the possibility of musculoskeletal injuries and skin ailments and thus should have basic first aid knowledge," Boulware et al., 2003, p. 292), obeying warnings (“... warning signs and safety messages should be strongly heeded by all visitors," Heggie et al., 2009, p. 103), bringing the proper equipment ("... it is important to carry the proper gear for the local area," Mason et al., 2013, p. 6), as well as advice for specific situations ("... tourists with asthma or pre-existing heart conditions should be discouraged from visiting areas such as sulfur banks where sulfur dioxide and other sulfate compounds are present in high volumes," Heggie, 2005, p. 130). Advice for specific situations was especially prevalent in articles about 


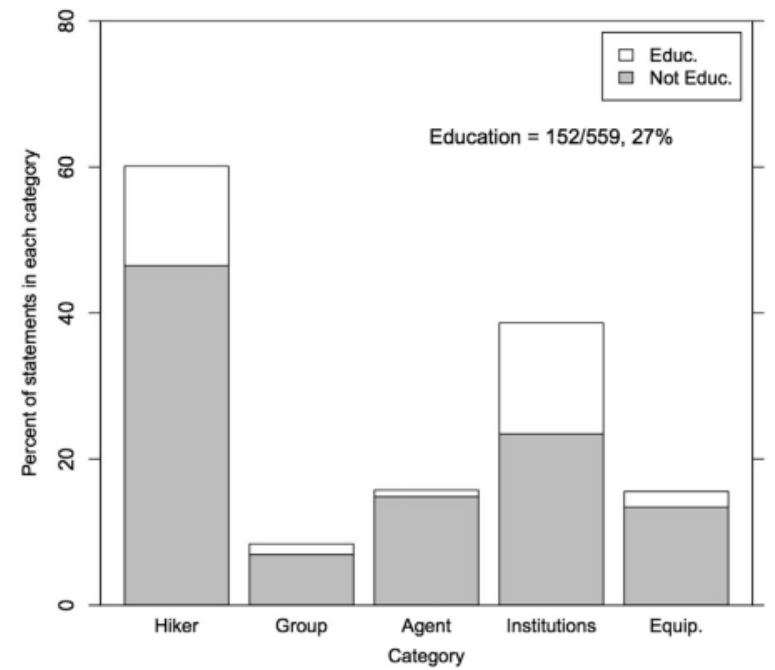

Fig. 2. Percent of educational and non-educational prevention recommendations in each Haddon matrix category. Categories are not mutually exclusive.

animal attacks ("Food should be kept in airtight storage containers well away from the sleeping area, preferably hung in or between trees," Floyd, 1999, p. 80).

Educational recommendations made up $23 \%$ of those targeting hikers, and most advised hiker education without specifying who should be in charge of such instruction or how it should be obtained or delivered ("These data should encourage visitor education about appropriate campfire and camp stove safety," Stephens et al., 2005, p. 196; "Prevention of injury and illness requires an awareness of risk that comes through education," Kogut \& Rodewald, 1994, p. 176; "Children should be educated about the potential dangers around animals," Langley \& Morrow, 1997, p. 12).

\subsection{Institutions and sociocultural practices}

The other major category of prevention recommendations targeted institutions and sociocultural practices. Many of these recommendations pertained to actions that institutions actually take after an incident to reduce incident severity ("First responders must be cognizant that SAR missions may be complicated by medical conditions that may predispose a victim to hypoglycemia, uncontrolled hypertension, or respiratory distress," Sadeghi et al., 2015, p. 163) or to gather data for planning, personnel deployment and capabilities, and facilities (“... increase the surveillance system's specificity for activities associated with outdoor recreational injuries," in order "to guide future outdoor recreational access, education, and health care planning," Flores et al., 2008 , p. 97). Institutional recommendations also pertained to preventing incidents, such as a recommendation that some national parks develop "preventative SAR techniques" (Heggie \& Heggie, 2008, p. $170)$ and recommendations to use "...more direct methods that communicate the risks and hazards" such as "... more personal contact between park staff and... hikers" (Heggie \& Heggie, 2004, p. 81).

Education was a focus of $39 \%$ of the institutional recommendations. These referred to providing training to both hikers ("Additional education could also be provided [by NOLS] regarding hiking on challenging terrain," Hamonko et al., 2011, p. 5) and personnel ("Future educational efforts should be focused on training rescuers in the initial response to acute myocardial infarction, common extremity injuries, and fatigue prevention and management," Welter et al., 2015, p. 554). Another main focus was recommendations about how institutions should reach the audience with educational messages, such as through warning signs, websites, courses, and printed material (“... pre-departure travel education efforts via the internet should be expanded for all park units," Heggie, 2008, p. 355).

\subsection{Agent of harm}

About equally prevalent in the articles were recommendations targeted at either the agent of harm or equipment. Recommendations pertaining to changing the agent of harm focused on avoiding either injury or illness. Illness prevention advice was often related to hygiene, water disinfection, and diet ("Hikers should also routinely disinfect water and avoid untreated surface water from streams or ponds," Boulware, 2004a, p. 32; "Glucose or carbohydrate replacement during prolonged exercise is recommended to delay metabolic exhaustion and fatigue," Backer et al., 1993, p. 403). Injury prevention was focused on the hikers ("... reduce the weight carried by participants," Hamonko et al., 2011, p. 5) as well as on the physical environment ("... safety measures need to be taken to better prevent injuries (such as railings or fences on trails or pathways...)," Baker \& McKay, 2010, p. 184). Educational recommendations in the agent of harm category were rare but pertained to teaching others how to avoid injury or illness ("... teaching and enforcing strict hygiene with food preparation," Gaudio et al., 2011, p. 369).

\subsection{Equipment}

Recommendations about equipment were typically specific suggestions for supplies needed to promote hygiene, appropriate clothing, or first aid supplies ("Because halogens do not kill Cryptosporidium species, and because filtration misses some viruses, optimal protection for all situations may require a 2-step process of either filtration or coagulation-flocculation, followed by halogenation," Backer, 2002, p. 362; “... recurrent ankle injuries might be prevented by high-top boots, an air splint, taping, ..." Gentile et al., 1992, p. 860). Educational recommendations generally referred to teaching about the proper use of equipment to avoid injury or illness ("... teaching students the proper use of camping stoves and knives," Gaudio et al., 2011, p. 369).

\subsection{Groups and relationships}

Finally, the smallest number of recommendations fell into the groups and relationships category. Some of these recommendations pertained to reducing the spread of illness within recreational groups ("Poor hygiene should be recognized as a contributor to the spread of gastrointestinal illness," Boulware et al., 2003, p. 292). Others recognized the role of group members in promoting safety practices ("Group norms and the social acceptability of behavior may act as powerful determinants of risk-taking behavior. The utilization of such factors may prove to be an effective means of ensuring compliance with "good practice," Powell, 2007, p. 12), and in particular the importance of watching out for children in recreational groups ("Because cougars tend to attack the last or isolated person in a group as well as attack from behind, it is advisable that adults hiking with children keep the children in front and keep close together," Kadesky et al., 1998, p. 864). Within this category were also recommendations pertaining to relationships external to the recreational activity such as advice for hikers' personal doctors ("Physicians need to discuss with hikers their potential health care needs," Crouse \& Josephs, 1993, p. 524). A few recommendations stressed the importance of educating people about safety practices involving groups and relationships ("educating people to notify others of their planned route may be a helpful means of shortening search and rescue," Ela, 2004, p. 16).

\section{Discussion}

The most striking result of this review is that the majority of prevention recommendations were directed at the hiker or host (60\%). In the Haddon matrix context, we think of this finding as reflecting a "blame the hiker" mindset. Rather than regarding an accident as solely due to the individual involved, the Haddon matrix framework promotes 
thinking about accidents as the results of the complex interaction of individuals with their social and physical environments (Haddon, 1980). In fact, Haddon (1980) bemoaned an approach to injury prevention focused solely on the host: “... many people still automatically assume that reduction of mechanical energy injuries... calls primarily for measures directed at individuals" (p. 419). Instead, the Haddon matrix asks what factors combine to influence a hiker to ignore a safety rule or engage in risky behavior? Intrinsic aspects of the hiker such as age, fitness, experience, knowledge, and risk-seeking personality characteristics are but one category of influences. Variables from other dimensions of the Haddon matrix can interact with aspects of the hiker to influence an accident: groups and relationships, the agent of harm, institutions and sociocultural practices, and equipment. Below we discuss the ways in which these influences are inevitably intertwined, and how this approach can provide a richer perspective that could lead to innovative solutions to common accidents and risky rule violations. For each category below we elaborate prevention examples that illustrate the different ways the influences interact.

\subsection{Aspects of the hiker}

Many recommendations attributed accidents to the hikers' lack of preparation, awareness, or knowledge. For example, Kogut and Rodewald (1994) found that hikers were carrying on average only half of the recommended first aid equipment and suggested that, “... hikers are making naive decisions not to carry certain items due to a lack of knowledge regarding the potential for injury or illness and their prevention" (p. 177). Perhaps due to the assumption that lack of knowledge resulted in the incident, a large proportion of prevention recommendations proposed educating the hiker. In conducting this review, the authors were disappointed by the lack of specificity in many of the education recommendations. Most "educate the hiker about $\mathrm{x}$ " recommendations did not specify who should do the instruction, when the instruction should occur, and how the content should be delivered. Some did not elaborate what the specific content should be. However, most education recommendations would normally be carried out by relevant institutions, such as National Parks, National Forests, outdoor education programs, or leaders in recreation organizations. Therefore, specific recommendations for hiker education should have a dual focus of not only encouraging hikers to seek out education, but also encouraging institutions to offer more accessible and effective educational opportunities.

Another example at the interface of the hiker and institutions is the prevention recommendation that hikers should obey safety guidelines, such as warning signs (e.g., Heggie, 2005; Heggie et al., 2009; Floyd, 1999). Failure to adhere to posted warnings is found in the research (Heggie \& Heggie, 2004), informally in reports of outdoor accidents in news media (Associated Press, 2016), and in agency investigations (Yellowstone National Park, 2016). For example, the final Yellowstone report of a 2016 fatality investigation included at least 20 photos illustrating the warning signs in the area of the accident. But a key question that needs further research examination is why hikers ignore warning signs. This may be partly due to internal aspects of the hiker, such as feeling like the warning does not apply to them (Oakes, Chapman, Borland, Balmford, \& Trotter, 2006), but it may also be due to the social situation or aspects of the warnings themselves. For example, when a hiker observes others off trail in violation of a warning sign, it is tempting to view those actions as safe and to follow suit. Or, should a hiker be regarded as at fault for having ignored a warning sign with a high density of information that requires high reading proficiency? In such a case, it is the role of institutions to construct more effective warnings, and we discuss this category of the Haddon matrix next.

\subsection{Institutions and sociocultural practices}

Institutionally established policies and structures, such as warning messages, trail markers, railings, rules, and trail conditions, interact with characteristics of visitors and their behaviors. Although the second highest category of prevention recommendations after the hiker pertained to institutions, we did not find any recommendations explicitly stating that warnings should be improved, or that their effectiveness should be studied. This deficit is in spite of the availability of a robust human factors literature on ways of improving the effectiveness of warnings (Rogers, Lamson, \& Rousseau, 2000; Wogalter, 1999). For example, if warnings are ignored, it is important to ask how to modify the environment and messaging. Future studies could examine factors such as whether warning signs have sufficient contrast with background to be noticed, if they are placed in an appropriate location near the hazard, if the print is large enough, whether visual icons are clearly understood by viewers, and if other aspects of the message content are clear (see Ballantyne \& Hughes, 2006, for a discussion of principles of interpretive and warning signs for nature visitation). In addition, there is research on framing message content in order to promote compliance with safety and resource protection guidelines (for example studies, see Hall, Ham, \& Lackey, 2010; Hockett \& Hall, 2007; Marschall, Granquist, \& Burns, 2017; Winter, 2006). However, researchers also note that many park messages are developed based on intuitions about what will be effective rather than on research (Hall et al., 2010), and some of these intuitions have been shown to contradict the research on message effectiveness (Winter, Sagarin, Rhoads, Barrett, \& Cialdini, 2000).

In the institutions category, we did find some prevention recommendations for alternatives to warning signs as means of communicating with visitors. Those recommendations included suggestions such as having rangers on popular trails at the most popular times of day for visitors (e.g., Noe et al., 2013), providing alternative and safer locations for scenic photographs (Girasek et al, 2016), and communicating with visitors prior to their visits via websites (e.g., Heggie, 2008). Some of these are similar to methods used at Grand Canyon, where "Preventative Search and Rescue Rangers" are on the most popular trails to discuss temperature, water, fitness, and hike planning with hikers. These techniques could be empirically examined to determine their effectiveness.

Interestingly, we found few recommendations for institutions to increase enforcement of rules through warnings or penalties. Only two papers contained such recommendations, and they pertained to enforcement of proper waste disposal and food storage (McLaughlin et al., 2005; Townes et al., 2000). This contrasts with research on preventing traffic accidents, where it is standard to discuss the "3 E's": Education, enforcement and engineering (Forward, 2009).

\subsection{Groups and relationships}

It is notable that our review found only $8 \%$ of prevention recommendations focusing on the hiker's social group. Perhaps this derives from the strong focus on individual hiker behavior. The importance of group behavior was recognized in prevention recommendations regarding the spread of gastrointestinal illnesses (e.g., Gentile et al., 1992), avoiding animal attacks (e.g., Kadesky et al., 1998), and in two papers mentioning that group norms for safety could provide an effective deterrent to risky behavior (Flores et al., 2008; Powell, 2007).

Research on social norms has revealed the powerful effects that other people can have on an individual's behavior. For example, if some individuals ignore warning signs or rules, others who see them are more likely to act similarly. This phenomenon can occur if the rule violators are other members of the hiker's immediate group or even if they are strangers. The interaction between social influences and individual factors is part of the well-known Theory of Planned Behavior which considers not only the role of individual attitudes and beliefs about 
behavioral control, but also social norms as predictors of behavior (Ajzen, 1991). Many studies have applied this theory to understand outdoor recreation behaviors or to test the effectiveness of educational messages in outdoor settings (e.g., Martin \& McCurdy, 2009; Reiner \& Lawson, 2009). In addition, the power of social influences might be harnessed to improve messages and warnings by using descriptive or injunctive norms (Cialdini et al., 2006). Injunctive social norms are beliefs about the social approval and disapproval of actions, whereas descriptive social norms are beliefs about what other people actually do. Descriptive social norms can be based on direct observations of others as well as indirect information. Although descriptive social norms are often inaccurate, as in college students' perceptions of the average alcohol consumption of other students, those descriptive norms are influential nonetheless (Schultz, Nolan, Cialdini, Goldstein, \& Griskevicius, 2007). The use of both injunctive and descriptive norms has been recommended to promote pro-environmental behavior, but to be effective, the two types of norms should be consistent (Cialdini, 2003).

One field experiment used these social norm concepts to deter rule violations in Arizona's Petrified Forest National Park (Cialdini et al., 2006). Signs with four different messages were presented for equal lengths of time at three different locations. Each hiking area was baited with petrified wood from the park's stock of wood that visitors had anonymously returned as an act of conscience. A sign with a negatively worded injunctive norm (an image of a hand taking wood with a red circle and bar superimposed on it and the words, "Please don't remove petrified wood from the park") yielded the least theft of petrified wood $(1.7 \%)$. In contrast, the negatively worded descriptive norm yielded the highest wood theft $(7.9 \%)$. The descriptive norm gave visitors information that, "... many visitors have removed the petrified wood from the park, changing the state of the Petrified Forest," and showed images of three visitors taking wood. Cialdini and colleagues lament that many public service messages muddle descriptive and injunctive social norms by saying, "Many people do $\mathrm{x}$," while simultaneously giving information that, "Doing $\mathrm{x}$ is bad" (see Schultz et al., 2007, for examples). Although the study of sign messaging in Petrified Forest National Park concerned damage to the natural resource rather than behavior dangerous to visitors, future research could explore similar strategies for rule violations that do entail danger. Another field study found similarly effective results for negatively worded injunctive norms on signs directing visitors to stay on trails (Winter, 2006). Signs enjoining visitors to stay on trails are commonly used to prevent hikers from encountering dangerous situations. The above concepts about signs and visitors illustrate how the Haddon matrix categories of "groups and relationships" relates to "institutions and sociocultural practices" as well as the "hiker."

\subsection{Equipment}

Equipment recommendations were relatively infrequent (16\%), and most were about getting the hiker to change by having and using specific equipment. "Appropriate footwear" was listed by several studies (e.g., Boore \& Bock, 2013; Schussman et al., 1990). Many outdoor safety sources have a list of 10 essential items to carry for emergency use, but we only found one study that surveyed hikers about whether they were carrying these items (Mason et al., 2013). Another study surveyed patients who had been rescued from a National Park, and found that only $13 \%$ said equipment or lack of equipment had contributed to the accident (Boore \& Bock, 2013). A few equipment recommendations regarding safety around animals also interfaced with institutions by suggesting that institutions require animal deterrent food storage, such as bear proof containers.

\subsection{Agent of harm}

The agent of harm was also infrequently referenced in the prevention recommendations (16\%) and showed overlap with equipment, as with the equipment recommendation for appropriate footwear. For example, through-hikers, such as on the Pacific Crest, Continental Divide, or Appalachian Trail, often experience paresthesias that can be reduced through lighter packs and footwear (Anderson et al., 2009). Agent of harm can also be seen to interact with groups and relationships, as with the transmission of organisms that cause diarrhea, either through use of a privy or group food preparation. There were few references to trail conditions as the agent of harm, and many of those suggested education of the hiker about trail conditions and terrain, hiking technique, or increasing the hiker's awareness of terrain (Attarian, 2015; Hung \& Townes, 2007; Schussman et al., 1990). We also found only one specific recommendation to improve trail conditions in spite of the nationwide deficit in trail maintenance funding (U.S. Government Accountability Office, 2013).

As discussed above, each Haddon matrix category interconnects with others to influence risk and prevention. A unique contribution of the present review is widening the conceptual framework of prevention in outdoor recreation settings. By viewing accidents as the product of complex interactions of individuals with their social and physical environments, novel methods for accident reduction may be introduced. Indeed, future researchers or outdoor recreation professionals could use the Haddon matrix as a technique for brainstorming possible prevention measures (as promoted by Runyan, 1998). Ideas generated through such a process, as well as the suggestions offered above based on this review, should then be empirically tested to establish their effectiveness. These tests might best be done in specific outdoor contexts because each setting has its own hazards. Such an undertaking would contribute to developing an evidence basis for prevention recommendations that could reduce hiking incidents.

\section{Limitations}

A strength of this paper is the application of the Haddon matrix, but there are systems-oriented methods of accident analysis that we did not use. In engineering, accident analysis aims to uncover the proximal and distal causes of accidents as well as organizational influences and interactions among the levels of a system (Becker, 2007; Salmon et al., 2012; Salmon, Goode, Lenné, Finch, \& Cassell, 2014). The Haddon matrix is not an accident analysis method, but focusses on categories for future prevention. Using a formal method of accident analysis might yield different categories for focusing prevention efforts. However, Salmon and colleagues, working with an outdoor accident database in New Zealand, commented that information in the accident reports is limited to only certain levels of the system (Salmon et al, 2014). Although some of the articles we reviewed are based on compilations of incident reports from agencies, not enough detail is present in the articles for complete accident analyses, and it is likely that the incident reports also lack sufficient detail for accident analysis.

This review also focused on hiking and excluded papers that pertained solely to snow sports, alpine climbing, biking, boating, motorized recreation, and swimming. Many of the recommendations that were found could apply to many different activities, but the prevalence of different types of recommendations might be changed if other activities are examined. For example, consideration of technical climbing or mountain biking might yield more equipment recommendations because they require specialized gear. As mentioned earlier, hiking was selected as the focus partly because a substantial proportion of outdoor recreation incidents involve hiking.

Different types of prevention recommendations might also be found by including more medically based articles that were excluded from this analysis, such as guidelines for medical practitioners, pre-participation screening guidelines for primary care practitioners, methods of differential diagnosis, and medical treatment methods for specific types of outdoor injuries and illnesses. Excluding these types of articles likely means that this paper may underestimate the category of institutional 
recommendations.

We also only included peer-reviewed published papers because scientific research can be very important in establishing public policies; however, bias toward publication of only studies with findings that either have statistical significance or appeal to the editors of a particular journal limits the sample of articles we found. In addition, although the prevention recommendations may not necessarily be central to the articles analyzing hiking illness and accident data, they were offered by the article authors as part of their consideration of outdoor incidents. In contrast to peer-reviewed scientific sources, there exists a robust "gray literature" and websites on hiking safety that we omitted. Many outdoor organizations provide safety advice or teach wilderness and hiking safety courses (including Navigators, Girl Scouts, American Hiking Society, Boy Scouts of America, REI, and Appalachian Trail Conservancy, to name a few). Examining the prevention recommendations for hiking in such sources would constitute a separate project.

Another limitation is that we excluded papers that used only nonU.S. hiking incidents in order to keep a somewhat homogeneous cultural context. Cultures and nations have different values with respect to individual versus collective responsibility, sizes of perceived social networks, and risk-taking (Weber \& Morris, 2010); preserving public land and management policies for public lands (Agnoletti \& Santoro, 2015); and preferences for hiking environments (Sayan, Krymkowski, Manning, Valliere, \& Rovelstad, 2013). It seemed best to restrict the articles and conclusions to the U.S. as a starting point for a compilation of prevention recommendations using the Haddon matrix, although an examination of cultural differences in prevention would be an interesting and important future endeavor.

\section{Conclusions}

By extracting prevention recommendations from articles that compiled hiking incidents and casting them in the framework of a Haddon matrix, this review has revealed a lack of comprehensive consideration of the levels of the sociocultural and environmental systems in which such incidents occur. Specifically, the critical components of social groups, agents of harm, and equipment seem to be under-represented in the prevention recommendations in the articles. The focus on the hiker, and educating the hiker, is reminiscent of Haddon's (1980) complaint that many people assume that the way to address accidents is at the individual level. In other situations of safety and prevention, all levels of a system are more often incorporated in prevention strategies (Goode, Read, van Mulken, Clacy, \& Salmon, 2016; Provonost, 2016). There are examples of this in outdoor recreation education, for instance in Cornell Outdoor Education programs "a culture of safety permeates the organization's operations" (Gaudio et al., 2011, p. 368). One way to move outdoor hiking accident prevention forward is to use the Haddon matrix categories as a springboard for empirical study of evidencebased prevention.

\section{References}

Agnoletti, M., \& Santoro, A. (2015). Cultural values and sustainable forest management: The case of Europe. Journal of Forest Research, 20, 438-444. http://dx.doi.org/10. 1007/s10310-015-0500-7.

Ajzen, I. (1991). The theory of planned behavior. Organizational Behavior and Human Decision Processes, 50(2), 179-211. http://dx.doi.org/10.1016/0749-5978(91) 90020-T.

Anderson, L. S., Rebholz, C. M., White, L. F., Mitchell, P., Curcio, E. P., Feldman, J. A., \& Kahn, J. H. (2009). The impact of footwear and packweight on injury and illness among long-distance hikers. Wilderness \& Environmental Medicine, 20(3), 250-256.

Associated Press (2016). June 9). Gruesome hot spring death highlights problems at Yellowstone. Retrieved from 〈http://www.denverpost.com/2016/06/09/gruesomehot-spring-death-highlights-problems-at-yellowstone/ $>$.

Attarian, A. (2015). Waterfall morbidity and mortality in North Carolina, 2001-2013. Wilderness and Environmental Medicine, 26, 105-107.

Attarian, A. A. (2010). A review of lightning safety education for outdoor adventure programs. Wilderness and Environmental Medicine, 21(2), 176-177. http://dx.doi.org/ 10.1016/j.wem.2009.12.011.

Backer, H. (2002). Water disinfection for international and wilderness travelers. Clinical Infectious Diseases, 34(3), 355-364.

Backer, H. D., Shopes, E., \& Collins, S. L. (1993). Hyponatremia in recreational hikers in Grand Canyon National Park. Journal of Wilderness Medicine, 4(4), 391-406. http:// dx.doi.org/10.1580/0953-9859-4.4.391.

Backer, H. D., Shopes, E., Collins, S. L., \& Barkan, H. (1999). Exertional heat illness and hyponatremia in hikers. American Journal of Emergency Medicine, 17(6), 532-539. http://dx.doi.org/10.1016/s0735-6757(99)90191-2.

Baker, J., \& McKay, M. P. (2010). Analysis of Emergency Medical Services activations in Shenandoah National Park from 2003 to 2007. Prehospital Emergency Care, 14(2), 182-186. http://dx.doi.org/10.3109/10903120903564506.

Ballantyne, R., \& Hughes, K. (2006). Using front-end and formative evaluation to design and test persuasive bird feeding warning signs. Tourism Management, 27, 235-246. http://dx.doi.org/10.1016/j.tourman.2004.09.005.

Becker, W. S. (2007). The Great Bear Wilderness disaster. Organizational Dynamics, 36, 363-376. http://dx.doi.org/10.1016/j.orgdyn.2007.06.003.

Boore, S. M., \& Bock, D. (2013aa). Ten years of search and rescue in Yosemite National park: Examining the past for future prevention. Wilderness and Environmental Medicine, 24, 2-7.

Boulware, D. R. (2003). Backpacking-induced paresthesias. Wilderness \& Environmental Medicine, 14(3), 161-166. http://dx.doi.org/10.1580/1080-6032(2003)14 [161:bp] $2.0 . \operatorname{co} ; 2$.

Boulware, D. R. (2004a). Influence of hygiene on gastrointestinal illness among wilderness backpackers. Journal of Travel Medicine, 11(1), 27-33.

Boulware, D. R. (2004b). Gender differences among long-distance backpackers: A prospective study of women Appalachian Trail backpackers. Wilderness \& Environmental Medicine, 15(3), 175-180. http://dx. doi.org/10.1580/1080-6032(2004) 15[175:gdalba] 2, 0.co;2.

Boulware, D. R., \& Beisang, A. A. (2005). Passive prophylaxis with permethrin-treated tents reduces mosquito bites among North American summer campers. Wilderness and Emvironmental Medicine, 16(1), 9-15.

Boulware, D. R., Forgey, W. W., \& Martin, W. J. (2003). Medical risks of wilderness hiking. American Journal of Medicine, 114(4), 288-293. http://dx.doi.org/10.1016/ s0002-9343(02)01484-8.

Brice, J. H., Studnek, J. R., Bighan, B. L., Martin-Gill, C., Custalow, C. B., Hawkins, E., \& Morrison, L. J. (2012). EMS provider and patient safety during response and transport: Proceedings of an ambulance safety conference. Prehospital Emergency Care, 16, 3-19. http://dx.doi.org/10.3109/10903127.2011.626106.

Burdick, T. E., \& Brozen, R. (2003). Wilderness event medicine. Wilderness \& Environmental Medicine, 14(4), 236-239. http://dx.doi.org/10.1580/10806032(2003)14[236:wem]2.0.co;2.

Burtscher, M., Pachinger, O., Schocke, M. F. H., \& Ulmer, H. (2007). Risk factor profile for sudden cardiac death during mountain hiking. International Journal of Sports Medicine, 28, 621-624. http://dx.doi.org/10.1055/s-2007-964850.

Chang, E C., Koval, E., Freer, L., \& Kraus, S. (2000). Planning for an annual episodic mass gathering: Emergency department and clinic utilization in Yellowstone. Wilderness \& Environmental Medicine, 11(4), 257-261. http://dx.doi.org/10.1580/10806032(2000)011[0257:pfaaem]2.3.co;2.

Cherington, M. (2001). Lightning injuries in sports - Situations to avoid. Sports Medicine, 31(4), 301-308. http://dx.doi.org/10.2165/00007256-200131040-00004.

Cialdini, R. B. (2003). Crafting normative messages to protect the environment. Current Directions in Psychological Science, 12, 105-109.

Cialdini, R. B., Barrett, D. W., Bator, R., Demaine, L., Sagarin, B. J., Rhoads, K. L., \& Winter, P. L. (2006). Managing social norms for persuasive impact. Social Influence, 1(1), 3-15. http://dx.doi.org/10.1080/15534510500181459.

Cordell, H. K. (2012). Outdoor recreation trends and futures: A technical document supporting the Forest Service 2010 RPA assessment. Asheville, NC: U.S. Department of Agriculture Forest Service. (Retrieved from) 〈www.srs.fs.usda.gov/pubs/gtr/gtr_srs150.pdf〉.

Cowdin, N. P. (1986). Conceptions and behaviors of recreationists regarding water quality in rocky Mountain National Park. Proceedings of the National Wilderness Research Conference, Fort Collins, 1985, 241-244.

Crouse, B. J., \& Josephs, D. (1993). Health-care needs of Appalachian Trail hikers. Journal of Family Practice, 36(5), 521-525.

DeClerck, M. P., Atterton, L. M., Seibert, T., \& Cushing, T. A. (2013). A review of Emergency Medical Services events in US national parks from 2007 to 2011. Wilderness \& Environmental Medicine, 24(3), 195-202.

Ela, G. K. (2004). Epidemiology of wilderness search and rescue in new Hampshire, 1999-2001. Wilderness \& Environmental Medicine, 15(1), 11-17. http://dx.doi.org/10. 1580/1080-6032(2004)015 [0011:eowsar]2.0.co;2.

Elliott, T. B., Elliott, B. A., \& Bixby, M. R. (2003). Risk factors associated with camp accidents. Wilderness \& Environmental Medicine, 14(1), 2-8. http://dx.doi.org/10. 1580/1080-6032(2003)014 [0002:rfawca]2.0.co;2.

Flores, A. H., Haileyesus, T., \& Greenspan, A. I. (2008). National estimates of outdoor recreational injuries treated in emergency departments, United States, 2004-2005. Wilderness \& Environmental Medicine, 19(2), 91-98. http://dx.doi.org/10.1580/07. weme-or-152.1.

Floyd, T. (1999). Bear-inflicted human injury and fatality. Wilderness and Environmental Medicine, 10, 75-87.

Forrester, J. D., \& Holstege, C. P. (2009). Injury and illness encountered in Shenandoah National Park. Wilderness \& Environmental Medicine, 20(4), 318-326.

Forward, S. E. (2009). An assessment of what motivates road violations. Transportation Research Part F, 12, 225-234.

Freer, L. (1999). Bear-human conflict: Who is the victim? Wilderness and Environmental Medicine, 10(2), 64-65.

Freer, L. (2004). North American wild mammalian injuries. Emergency Medicine Clinics of 
North America, 22(2), 445-473. http://dx.doi.org/10.1016/j.emc. 2004.01.008.

Gardner, T. B., \& Hill, D. R. (2002). Illness and injury among long-distance hikers on the long trail, Vermont. Wilderness \& Environmental Medicine, 13(2), 131-134. http://dx. doi.org/10.1580/1080-6032(2002)013[0131:iaiald] 2.0.co;2.

Gaudio, F. G., Greenwald, P. W., \& Holton, M. (2011). Injury and illness in college outdoor education. Wilderness and Emvironmental Medicine, 21, 363-370.

Gentile, D. A., Morris, J. A., Schimelpfenig, T., Bass, S. M., \& Auerbach, P. S. (1992) Wilderness injuries and illnesses. Annals of Emergency Medicine, 21(7), 853-861. http://dx.doi.org/10.1016/s0196-0644(05)81034-0.

Girasek, D. C., Marschall, J. S., \& Pope, D. (2016). Understanding hikers who approached a hazardous river in Yosemite National Park. Injury Prevention, 22, 110-116. http:// dx.doi.org/10.1136/injuryprev-2015-041625.

Goode, N., Read, G. J. M., van Mulken, M. R. H., Clacy, A., \& Salmon, P. M. (2016), Designing system reforms: Using a systems approach to translate incident analyses into prevention strategies. Frontiers in Psychology, 7, 1974. http://dx.doi.org/10. 3389/fpsyg.2016.01974.

Goode, N., Salmon, P. M., Lenné, M. G., \& Finch, C. F. (2015). Beyond people, equipment and environment: Is a system approach of accident causation required to understand injuries and near misses during outdoor activities? Procedia Manufacturing, 3, $1125-1131$.

Goodman, T., Iserson, K. V., \& Strich, H. (2001). Wilderness mortalities: A 13-year experience. Annals of Emergency Medicine, 37(3), 279-283. http://dx.doi.org/10.1067/ mem.2001.112256.

Grissom, C. K., Thomas, F., \& James, B. (2006). Medical helicopters in wilderness search and rescue operations. Air Medical Journal, 25(1), 18-25.

Gruen, R. L. (2009). Crocodile attacks in Australia: Challenges for injury prevention and trauma care. World Journal of Surgery, 33, 1554-1561.

Haddon, W. (1980). Advances in the epidemiology of injuries as a basis for public policy. Public Health Reports, 95(5), 411-421.

Haddon, W., Jr. (1995). Energy damage and the 10 countermeasure strategies. Injury Prevention, 1, 40-44.

Hall, T. E. Ham, S. H., \& Lackey, B. K. (2010). Comparative evaluation of the attention capture and holding power of novel signs aimed at park visitors. Journal of Interpretation Research, 15(1), 15-36.

Hamonko, M. T., McIntosh, S. E., Schimelpfenig, T., \& Leemon, D. (2011). Injuries related to hiking with a pack during National outdoor leadership school courses: A risk factor analysis. Wilderness \& Environmental Medicine, 22(1), 2-6. http://dx.doi.org/10. 1016/j.wem.2010.09.010

Heggie, T. W. (2005). Reported fatal and non-fatal incidents involving tourists in Hawaii Volcanoes National Park, 1992-2002. Travel Medicine and Infectious Disease, 3, 123-131. http://dx.doi.org/10.1016/j.tmaid. 2004.09.004.

Heggie, T. W. (2008). Search and rescue in Alaska's national parks. Travel Medicine and Infectious Disease, 6, 355-361. http://dx.doi.org/10.1016/j.tmaid.2008.07.002.

Heggie, T. W. (2010). Paediatric and adolescent sport injury in the wilderness. British Journal of Sports Medicine, 44(1), 50-55. http://dx.doi.org/10.1136/bjsm.2009. 068049.

Heggie, T. W., \& Amundson, M. E. (2009). Dead men walking: Search and rescue in US national parks. Wilderness \& Environmental Medicine, 20(3), 244-249.

Heggie, T. W., \& Heggie, T. M. (2004). Viewing lava safely: An epidemiology of hiker injury and illness in Hawaii volcanoes National Park. Wilderness \& Environmental Medicine, 15(2), 77-81. http://dx.doi.org/10.1580/1080-6032(2004) 015[0077:vlsaeo]2.0.co;2.

Heggie, T. W., \& Heggie, T. M. (2008). Search and rescue trends and the emergency medical service workload in Utah's National Parks. Wilderness \& Evvironmental Medicine, 19(3), 164-171. http://dx.doi.org/10.1580/07-weme-or-178.1.

Heggie, T. W., \& Heggie, T. M. (2009a). Search and rescue trends associated with recreational travel in US national parks. Journal of Travel Medicine, 16, 23-27. http:// dx.doi.org/10.1111/j.1708-8305.2008.00269.x.

Heggie, T. W., \& Heggie, T. M. (2009b). Search and rescue trends associated with recreational travel in US National Parks. Journal of Travel Medicine, 16(1), 23-27. http://dx.doi.org/10.1111/j.1708-8305.2008.00269.x.

Heggie, T. W., Heggie, T. M., \& Heggie, T. J. (2009). Death by volcanic laze. Wilderness \& Environmental Medicine, 20(1), 101-103.

Heggie, T. W., Heggie, T. M., \& Kliewer, C. (2008). Experience your America: National Park Service. Journal of Travel Medicine, 15(6), 404-411. http://dx.doi.org/10.1111/ j.1708-8305.2008.00235.x.

Ho, H. C., Speck, C. S., \& Kumasaki, J. (2009). Visitor injuries in Hawai'i. Hawaii Medical Journal, 68(11), 279-283.

Hockett, K. S., \& Hall, T. E. (2007). The effect of moral and fear appeals on park visitors' beliefs about feeding wildlife. Journal of Interpretation Research, 12(1), 5-27.

Hung, E. K., \& Townes, D. A. (2007). Search and rescue in Yosemite National Park: A 10year review. Wilderness \& Environmental Medicine, 18(2), 111-116. http://dx.doi.org/ 10.1580/06-weme-or-022r1.1.

Hurtado, T. R. (2010). Search and rescue activity on Denali, 1990 to 2008. Wilderness and Environmental Medicine, 21(2), 98-99. http://dx.doi.org/10.1016/j.wem.2010.01. 007.

Johnson, J., Maertins, M., Shalit, M., Bierbaum, T. J., Goldman, D. E., \& Lowe, R. A. (1991). Wilderness emergency medical services: The experiences at Sequoia and Kings Canyon National Parks. American Journal of Emergency Medicine, 9(3), 211-216.

Johnson, R. M., Huettl, B., Kocsis, V., Chan, S. B., \& Kordick, M. F. (2007). Injuries sustained at Yellowstone National Park requiring emergency medical system activation. Wilderness \& Environmental Medicine, 18(3), 186-189. http://dx.doi.org/10.1580/06weme-or-046r1.1.

Kadesky, K. M., Manarey, C., Blair, G. K., Murphy, J. J., III, Verchere, C., \& Atkinson, K. (1998). Cougar attacks on children: Injury patterns and treatment. Journal of Pediatric Surgery, 33, 863-865.
Kaplan, S., \& Berman, M. G. (2011). Directed attention as a common resource for executive functioning and self-regulation. Perspectives in Psychological Science, 5(1), 43-57.

Knott, J. W. (2011). Causes of injuries in the mountains: A review of worldwide reports into accidents in mountaineering. Journal of the Royal Army Medical Corps, 157(1), 92-99.

Kogut, K. T., \& Rodewald, L. E. (1994). A field study of the emergency preparedness of wilderness hikers. Journal of Wilderness Medicine, 5(2), 171-178. http://dx.doi.org/ 10.1580/0953-9859-5.2.171.

Krippendorff, K. (2004). Content analysis: An introduction to its methodology (2nd ed.). Thousand Oaks, CA: Sage Publications.

Langley, R. L. (2005). Alligator attacks on humans in the United States. Wilderness and Environmental Medicine, 16(3), 119-124.

Langley, R. L. (2010). Adverse encounters with alligators in the United States: An update. Wilderness and Environmental Medicine, 21(2), 156-163. http://dx.doi.org/10.1016/j. wem.2010.02.002.

Langley, R. L., \& Morrow, W. E. (1997). Deaths resulting from animal attacks in the United States. Wilderness and Environmental Medicine, 8, 8-16.

Lathrop, S. L. (2007). Animal-caused fatalities in New Mexico, 1993-2004. Wilderness and Emvironmental Medicine, 18(4), 288-292.

Leemon, D., \& Schimelpfenig, T. (2003). Wilderness injury, illness, and evacuation: National outdoor leadership school's incident profiles, 1999-2002. Wilderness \& Environmental Medicine, 14(3), 174-182. http://dx.doi.org/10.1580/10806032(2003)14[174:wiiaen]2.0.co;2.

Leveson, N. (2004). A new accident model for engineering safer systems. Safety Science, 42(4), 237-270.

Marschall, S., Granquist, S. M., \& Burns, G. L. (2017). Interpretation in wildlife tourism: Assessing the effectiveness of signage on visitor behaviour at a seal watching site in Iceland. Journal of Outdoor Recreation and Tourism, 17, 11-19. http://dx.doi.org/10. 1016/j.jort.2016.11.001.

Martin, S. R., \& McCurdy, K. (2009). Wilderness food storage in Yosemite: Using the theory of planned behavior to understand backpacker canister use. Human Dimensions of Wildlife, 14(3), 206-218.

Mason, R. C., Suner, S., \& Williams, K. A. (2013). An analysis of hiker preparedness: A survey of hiker habits in New Hampshire. Wilderness \& Environmental Medicine, 24(3), 221-227.

McIntosh, S. E., Brillhart, A., Dow, J., \& Grissom, C. K. (2010). Search and rescue activity on Denali, 1990 to 2008. Wilderness \& Environmental Medicine, 21, 103-108.

McIntosh, S. E., Leemon, D., Visitacion, J., Schimelpfenig, T., \& Fosnocht, D. (2007). Medical incidents and evacuations on wilderness expeditions. Wilderness \& Environmental Medicine, 18(4), 298-304. http://dx.doi.org/10.1580/07-weme-or093r1.1.

McLaughlin, J. B., Gessner, B. D., \& Bailey, A. M. (2005). Gastroenteritis outbreak among mountaineers climbing the West Buttress route of Denali - Denali National Park, Alaska. June 2002 Wilderness and Environmental Medicine, 16(2), 92-96.

Montalvo, R., Wingard, D. L., Bracker, M., \& Davidson, T. M. (1998). Morbidity and mortality in the wilderness. Western Journal of Medicine, 168(4), 248-254.

Morandi, N., \& Williams, J. (1997). Snakebite injuries: Contributing factors and intentionality of exposure. Wilderness and Environmental Medicine, 8(3), 152-155.

Mort, A., \& Godden, D. (2011). Injuries to individuals participating in mountain and wilderness sports: A review. Clinical Journal of Sport Medicine, 21(6), 530-536.

Newman, L. M., Diekema, D. S., Shubkin, C. D., Klein, E. J., \& Quan, L. (1998). Pediatric wilderness recreational deaths in western Washington State. Annals of Emergency Medicine, 32(6), 687-692. http://dx.doi.org/10.1016/s0196-0644(98)70068-x.

Noe, R. S., Choudhary, E., Cheng-Dobson, J., Wolkin, A. F., \& Newman, S. B. (2013). Exertional heat-related illnesses at the Grand Canyon National Park, 2004-2009. Wilderness \& Environmental Medicine, 24(4), 422-428.

Oakes, W., Chapman, S., Borland, R., Balmford, J., \& Trotter, L. (2006). "Bulletproof skeptics in life's jungle": Which self-exempting beliefs about smoking most predict lack of progression towards quitting? Preventative Medicine, 39, 776-782. http://dx. doi.org/10.1016/j.ypmed.2004.03.001.

O'Neil, M. E., Mack, K. A., Gilchrist, J., \& Wozniak, E. J. (2007). Snakebite injuries treated in United States emergency departments, 2001-2004. Wilderness and Environmental Medicine, 18(4), 281-287.

Paton, B. C. (1992). Health, safety, and risk in outward bound. Journal of Wilderness Medicine, 3(2), 128-144. http://dx.doi.org/10.1580/0953-9859-3.2.128.

Platts-Mills, T. F., \& Hunold, K. M. (2013). Increase in older adults reporting mountaineering-related injury or illness in the United States, 1973-2010. Wilderness and Emvironmental Medicine, 24(1), 86-88. http://dx.doi.org/10.1016/j.wem.2012.08. 014.

Pope, K., \& Martin, S. R. (2011). Visitor perceptions of technology, risk, and rescue in wilderness. International Journal of Wilderness 17(2), 19-26.

Powell, C. (2007). The perception of risk and risk taking behavior: Implications for incident prevention strategies. Wilderness and Environmental Medicine, 18, 10-15.

Provonost, P. J. (2016). Toward eliminating all harms. Quality Management in Health Care, 25(3), 185-186. http://dx.doi.org/10.1097/QMH.0000000000000100.

Rasmussen, J. (1997). Risk management in a dynamic society: A modelling problem. Safety Science, 27(2/3), 183-213.

Reiner, N., \& Lawson, S. R. (2009). Improving the efficacy of visitor education in Haleakalā National Park using the theory of planned behavior. Journal of Interpretation Research, 14(2), 21-45.

Rogers, W. A., Lamson, N., \& Rousseau, G. K. (2000). Warning research: An integrative perspective. Human Factors 2000, 102-139.

Rotz, L., Callejas, L., McKechnie, D., Wolfe, D., Gaw, E., Hathcock, L., \& Childs, J. (1998). An epidemiologic and entomologic investigation of a cluster of Rocky Mountain spotted fever cases in Delaware. Delaware Medical Journal, 70(6), 285-291. 
Runyan, C. W. (1998). Using the Haddon matrix: Introducing the third dimension. Injury Prevention, 4, 302-307.

Runyan, C. W. (2003). Introduction: Back to the future - Revisiting Haddon's conceptualization of injury epidemiology and prevention. Epidemiologic Reviews, 25, 60-64. http://dx.doi.org/10.1093/epirev/mxg005.

Runyan, C. W., \& Baker, S. P. (2009). Preventing injuries by understanding energy damage. Bulletin of World Health Organization, 87, 402-403. http://dx.doi.org/10.2471/ BLT.09.063586,

Runyan, C. W., \& Yonas, M. (2008). Conceptual frameworks for developing and comparing approaches to improve adolescent motor-vehicle safety. American Journal of Preventive Medicine, 35(3S), S336-S342. htt://dx.doi.org/10.1016/j.amepre.2008. 06.019.

Russell, K. W., Weber, D. C., Scheele, D. O., Ernst, R. P., Kanaan, N. K., Smith, W. R., \& Wheeler, A. R. (2013). Search and rescue in the intermountain west states. Wilderness and Environmental Medicine, 24, 429-433.

Sadeghi, R., Konwinski, J. C. \& Cydulka, R. K. (2015), Adirondack Park incidents: A retrospective review of search and rescue reports from 2008 and 2009. Wilderness \& Environmental Medicine, 26(2), 159-163.

Salmon, P. M., Cornelissen, M., \& Trotter, M. J. (2012). Systems-based accident analysis methods: A comparison of Accimap, HFACS, and STAMP. Safety Science, 50, 1158-1170.

Salmon, P. M., Goode, N., Lenné, M. G., Finch, C. F., \& Cassell, E (2014). Injury causation in the great outdoors: A systems analysis of led outdoor activity injury incidents. Accident Analysis and Prevention, 63, 111-120.

Sayan, S., Krymkowski, D. H., Manning, R. E., Valliere, W. A., \& Rovelstad, E. L. (2013). Cultural influence on crowding norms in outdoor recreation: A comparative analysis of visitors to national parks in Turkey and the United States. Environmental Management, 52, 493-502. http://dx.doi.org/10.1007/s00267-013-0076-y.

Schmidt, T. A., Federiuk, C. S., Zechnich, A., Forsythe, M., Christie, M., \& Andrews, C. (1996). Advanced life support in the wilderness: 5-year experience of the Reach and Treat Team. Wilderness \& Environmental Medicine, 7(3), 208-215. http://dx.doi.org/ 10.1580/1080-6032(1996)007[0208:alsitw]2.3.co;2.

Schultz, P. W., Nolan, J. M., Cialdini, R. B., Goldstein, N. J., \& Griskevicius, V. (2007). The constructive, destructive, and reconstructive power of social norms. Psychological Science, 18, 429-434.

Schussman, L. C., Lutz, L. J., Shaw, R. R., \& Bohn, C. R. (1990). The epidemiology of mountaineering and rock climbing accidents. Journal of Wilderness Medicine, 1, 235-248.

Shepherd, S. M., Mills, A., \& Shoff, W. H. (2014). Human attacks by large felid carnivores in captivity and in the wild. Wilderness and Environmental Medicine, 25(2), 220-230. http://dx.doi.org/10.1016/j.wem.2014.01.005.

Stephanides, S. L., \& Vohra, T. (2007). Injury patterns and first aid training among canyoneers. Wilderness and Environmental Medicine, 18, 16-19.

Stephens, B. D., Diekema, D. S., \& Klein, E. J. (2005ab). Recreational injuries in Washington state National Parks. Wilderness \& Environmental Medicine, 16(4), 192-197. http://dx.doi.org/10.1580/1080-6032(2005)16[192:riiwsn]2.0.co;2.

Stewart, W., Cole, D., Manning, R., Valliere, W., Taylor, J., \& Lee, M. (2000). Preparing for a day hike at Grand Canyon: What information is useful? USDA Forest Service Proceedings, 4, 221-225.

Thompson, C. W., \& Aspinall, P. A. (2011). Natural environments and their impact on activity, health, and quality of life. Applied Psychology: Health and Well-being, 3(3), 230-260.

Townes, D. A., Laughlin, M. K., \& Rubio-Derhammer, D. (2000). The black bears of Yosemite National Park: Bear-induced injuries-the role of improper food storage. Wilderness and Environmental Medicine, 11(1), 67-68.
Trayers, F. J. (2004). Wilderness preventive medicine. Wilderness and Environmental Medicine, 15(1), 1-3.

Twombly, S. E, \& Schussman, L. C. (1995). Gender differences in injury and illness rates on wilderness backpacking trips. Wilderness \& Emvironmental Medicine, 6(4), 363-376. http://dx.doi.org/10.1580/1080-6032(1995)006[0363:gdiiai]2.3.co;2.

U.S. Government Accountability Office (2013). Forest service trails: Long and short-term improvements could reduce maintenance backlog and enhance system sustainability. Washington, DC: U.S. Government Accountability Office. (Retrieved from) (http:// www.gao.gov/products/GAO-13-618>.

Vann, R. D., Pollock, N. W., Pieper, C. F., Murdoch, D. R., Muza, S. R., Natoli, M. J., \& Wang, L. Y. (2005). Statistical models of acute mountain sickness. High Altitude Medicine \& Biology, 6(1), 32-42. http://dx.doi.org/10.1089/ham.2005.6.32.

Wagner, D. R., Fargo, J. D., Parker, D., Tatsugawa, K., \& Young, T. A. (2006). Variables contributing to acute mountain sickness on the summit of Mt Whitney. Wilderness and Environmental Medicine, 17(4), 221-228.

Weber, E. U., \& Morris, M. W. (2010). Culture and judgment and decision making: The constructivist turn. Perspectives on Psychological Science, 5 (410-410. doi: 10.1 177/ 1745691610375556).

Weichenthal, L., Allen, J., Davis, K. P., Campagne, D., Snowden, B., \& Hughes, S. (2011), Lightning safety awareness of visitors in three California national parks. Wilderness and Environmental Medicine, 22, 257-261.

Weichenthal, L. A., \& Hendey, G. (1998). Altitude-related illness in two California national parks. Wildemess \& Environmental Medicine, 9(1), 28-31. http://dx.doi.org/10. 1580/1080-6032(1998)009 [0028:ariitc]2.3.co;2.

Welch, T. P. (1997). Data-based selection of medical supplies for wilderness travel. Wilderness \& Environmental Medicine, 8(3), 148-151. http://dx.doi.org/10.1580/ 1080-6032(1997)008[0148:dbsoms] 2.3.co;2.

Welter, C. R., Sholl, J. M., Strout, T. D., \& Woodard, B. (2015). Epidemiology of search and rescue in Baxter State Park: Dangers of descent and fatigue. Wilderness and Environmental Medicine, 26, 549-554.

Windsor, J. S., Firth, P. G., Grocott, M. P., Rodway, G. W., \& Montgomery, H. E. (2009). Mountain mortality: A review of deaths that occur during recreational activities in the mountains. Postgraduate Medical Journal, 85(1004), 316-321. http://dx.doi.org/ $10.1136 /$ pgmj.2009.078824.

Winter, P. L. (2006). The impact of normative message types on off-trail hiking. Joumal of Interpretation Research, 11(1), 35-52.

Winter, P. L., Sagarin, B. J., Rhoads, K., Barrett, D. W., \& Cialdini, R. B. (2000). Choosing to encourage or discourage: Perceived effectiveness of prescriptive and proscriptive messages. Environmental Management, 2(6), 588-594.

Wogalter, M. S. (1999). Factors influencing the effectiveness of warnings. In H. J. G. Zwaga, T. Boersema, \& H. C. M. Hoonhout (Eds.). Visual information for everyday use: Design and research perspectives (pp. 93-110). London, UK: Taylor \& Francis Ltd.

Yellowstone National Park (2016). Scott Fatality Report, redacted version. Retrieved from 〈http://static.lakana.com/bmg-kecitv-media-us-east-1/document dev/2016/11/15/ YEL_L_Scott_Fatality_IncidentReport_NP16070606_1479250828406_4741230_ver1.0. pdf).

Zarnoch, S. J., Bowker, J. M., \& Cordell, H. K. (2011). A mixed-modes approach for estimating hiking on trails through diverse forest landscapes: The case of the Appalachian Trail. Canadian Journal of Forestry Research, 41, 2346-2358.

Zell, S. C. (1992). Epidemiology of wilderness-acquired diarrhea-Implications for prevention and treatment. Journal of Wilderness Medicine, 3(3), 241-249. http://dx.doi. org/10.1580/0953-9859-3.3.241.

Zell, S. C., \& Sorenson, S. K. (1993). Cyst acquisition rate for Giardia-lamblia in backcountry travelers to Desolation Wilderness, Lake Tahoe. Journal of Wilderness Medicine, 4(2), 147-154. http://dx.doi.org/10.1580/0953-9859-4.2.147. 